\title{
Responsiveness of the Canadian Occupational Performance Measure
}

\author{
Isaline C. J. M. Eyssen, MSc, OT; ${ }^{*}$ Martijn P. M. Steultjens, PhD ${ }^{2}$ Tanja A. M. Oud, OT; ${ }^{3}$ E. Marije Bolt, \\ OT; ${ }^{3}$ Anke Maasdam, OT; ${ }^{1}{\text { Joost Dekker, } \text { PhD }^{1,4}}^{1,4}$ \\ ${ }^{1}$ Department of Rehabilitation Medicine, VU (Vrije Universiteit) University Medical Centre, Amsterdam, the Nether- \\ lands; ${ }^{2}$ School of Health, Glasgow Caledonian University, Glasgow, Scotland; ${ }^{3}$ Department of Rehabilitation, Aca- \\ demic Medical Centre, Amsterdam, the Netherlands; ${ }^{4}$ EMGO (Extramuraal Geneeskundig Onderzoek) Institute for \\ Health and Care Research and Department of Psychiatry, VU University Medical Centre, Amsterdam, the Netherlands
}

\begin{abstract}
This study evaluated the responsiveness of the Canadian Occupational Performance Measure (COPM), an individualized, client-centered outcome measure for the identification and evaluation of self-perceived occupational performance problems. We recruited 152 consecutive patients with various diagnoses, admitted to the outpatient clinic of two occupational therapy departments, to complete a COPM interview and three self-reported health status questionnaires on two occasions: prior to the start of occupational therapy treatment and 3 months later. The three questionnaires were the Sickness Impact Profile (SIP68), the Disability and Impact Profile (DIP), and the Impact on Participation and Autonomy (IPA). We assessed criterion responsiveness by calculating the area under the curve (AUC) for the receiver operating characteristic curve and the optimal cutoff values for the COPM scores. To determine construct responsiveness, we calculated correlations between the change in COPM scores and the change in the SIP68, DIP, and IPA scores. The AUC ranged from 0.79 to 0.85 , and the optimal cut-off values for the performance scores and satisfaction scores ranged from 0.9 to 1.9. We found significant positive correlations between the COPM scores and the SIP68, DIP, and IPA scores. The capability of the COPM to detect changes in perceived occupational performance issues is supported.
\end{abstract}

Key words: client-centered, COPM, needs assessment, occupational therapy, outcome assessment, patient participation, patient satisfaction, psychometrics, rehabilitation, treatment outcome.

\section{INTRODUCTION}

In rehabilitation, reducing disabilities and attaining independence and self-determination are important goals [1]. Assessment should therefore focus on disabilities and various aspects of occupational performance [2-3]. Occupational performance can be defined as the ability to choose, organize, and satisfactorily perform meaningful actions that are needed to look after oneself, enjoy life, and contribute to the social and economic fabric of a community [4]. This implies that not all clients need to share the same definition of enhanced occupational performance [5] and that not all clients with the same clinical status have the same goals or responses to treatment. Although many physiological measures provide clinicians with information, they often correlate poorly with functional capacity and well-being, the areas that are most important for clients [6]. A client-centered evalua-

\footnotetext{
Abbreviations: AUC $=$ area under the curve, $\mathrm{COPM}=$ Canadian Occupational Performance Measure, DIP = Disability and Impact Profile, IPA = Impact on Participation and Autonomy, ROC $=$ receiver operating characteristic, SIP68 $=$ Sickness Impact Profile, VU = Vrije Universiteit.

${ }^{*}$ Address all correspondence to Isaline C. J. M. Eyssen, MSc, OT; VU University Medic al Centre, Department of Rehabilitation Medicine/Occupational Therapy, PO Box 7057, 1007 MB Amsterdam, the Netherl ands; +31-204440012; fax: +31-20-4440006. Email: i.evssen@vumc.nl DOI:10.1682/JRRD.2010.06.0110
} 
tion of occupational performance, i.e., with the Canadian Occupational Performance Measure (COPM) [7], can help account for individual changes.

The COPM is an outcome measure designed to help clients identify, prioritize, and evaluate important issues they encounter in occupational performance [7]. This individualized outcome measure is used to assess a client's self-perception of actual performance and satisfaction with this performance over time. The assessment is conducted with a semistructured interview format and a structured scoring method and aims to assess change in a client's self-perception in occupational performance over time [7]. The conceptual basis of the COPM is derived from the Canadian Model of Occupational Performance, which is now extended to the Canadian Model of Occupational Performance and Engagement [4,7-8].

The clinimetric properties of the COPM have been studied in various situations. The reproducibility of the performance and satisfaction scores was found to be poor for the individually identified problems and moderate to high for the scores averaged over all the problems identified by a client [7,9-13]. Supportive evidence was found for the content, convergent, and divergent validities of the COPM [2,7,9,11,13-18]. Clinical utility, evaluated in a number of different studies, supported the use of the COPM for a variety of clients in different settings $[13,17,19-26]$. The COPM is designed to not only identify the client's perceived problems but also determine whether these problems have changed over time. The capability of a measure to detect change over time is referred to as its responsiveness [27-28].

The difference between validity and responsiveness is that validity refers to the validity of a single score and responsiveness refers to the validity of a change score [29]. As a logical consequence, criterion and construct responsiveness can be defined analogous to criterion and construct validity [29]. Criterion responsiveness is defined as the extent to which change in scores on a particular instrument relates to change in the gold standard. Construct responsiveness is defined as the extent to which change in scores on a particular instrument relates to change in other measures.

Various approaches exist for measuring responsiveness [28-32]. Inappropriate measures of responsiveness are the use of effect sizes and related measures such as standardized response mean and relative efficacy statistics [33]. A suitable method to assess responsiveness is calculating change scores for clients whose health is expected to have changed and to examine the correlation with corresponding changes in a reference measure or transition indices [30-32].

Several studies have indicated that the COPM is sensitive to change [2-3,7,12-13,20,34-35]. However, some of these studies are unpublished [7], used no criterion standard [3,7], or focused on a small study population [12,34] or specific diagnoses [20,34-35]. Therefore, the responsiveness of the COPM needs to be further evaluated.

The main objective of the present study was to evaluate the responsiveness of the COPM in a population of outpatients receiving occupational therapy interventions. Our evaluation was based on two research questions:

1. To what extent is the COPM able to detect improvement over time (criterion responsiveness)?

2. To what extent do changes in the COPM correlate with changes in other measures (construct responsiveness)?

Additionally, we evaluated the feasibility of the COPM and the correlation between the satisfaction and performance scores of the COPM.

\section{METHODS}

\section{Study Population and Assessors}

We recruited consecutive clients with various conditions who were newly referred to the outpatient occupational therapy departments of the Academic Medical Centre and the VU (Vrije Universiteit) University Medical Centre in Amsterdam. All clients received oral and written information about the study. Our intent was to include 150 clients, 75 in each center.

Inclusion criteria were 18 years or older, perceived limitations in more than one activity of daily living, and an outpatient treatment indication for occupational therapy. Clients who were currently receiving occupational therapy or had insufficient understanding of the Dutch language were excluded. Written informed consent was obtained from all participants.

Four assessors, two in each hospital, collected the data. They were all occupational therapists trained in administering the COPM. The assessors were not involved in the therapy sessions; the assessments were performed independently from the provided occupational therapy.

\section{Instruments}

The official Dutch translation of the COPM was used [36]. With the COPM, the therapist helps the client identify 
activities that the client "wants, needs, or is expected to perform" [7] and in which the client experiences problems with the actual performance or is dissatisfied with the level of performance. Accordingly, the client prioritizes up to five problems that are the most urgent or important and rates each of these problems on an ordinal 10-point scale regarding performance (where $1=$ "not able to do it at all" and $10=$ "able to do it extremely well") and satisfaction (where $1=$ "not satisfied at all" and $10=$ "extremely satisfied"). We obtained the mean scores for performance and satisfaction by summing the ratings for performance and satisfaction over the prioritized problems and dividing them by the number of prioritized problems. For an evaluation over time, at a later date the client again rates the performance and satisfaction regarding the prioritized problems of the first COPM interview. Mean scores can be compared with the mean scores of the first COPM.

To assess the criterion responsiveness, we used a transition index [37-38] to measure the perceived change in the problems as prioritized by the COPM. The perceived change in problems was graded on a 7-point ordinal scale, where 1 = "totally diminished" and 7 = "much worse." The transition index was pretested in a small group ( $n=$ 10 outpatients) and did distinguish between improved and unimproved patients. Patient-reported health transition questions that describe the magnitude and direction of change in general or specific health over a given period are a valid approach to measuring change and have been widely used as external criteria in the evaluation of responsiveness [38-39].

We assessed the construct responsiveness by comparing the COPM scores with the scores for the Sickness Impact Profile (SIP68), the Disability and Impact Profile (DIP), and the Impact on Participation and Autonomy (IPA). All these instruments include scales and/or subscales on the activities and participation domain of the International Classification of Functioning, Disability and Health [40] and aim to measure the impact or importance of a condition on functioning.

The SIP68, a generic measure used for assessing the impact of illness on daily functioning and behavior [4142], consists of 68 items that are all dichotomously scored. The items are categorized into six subscales: somatic autonomy (e.g., getting dressed, transfers), mobility control (behavior related to walking and arm function), psychological autonomy and communication (e.g., concentration, alertness, talking), emotional stability (the effect of health status on emotional behavior), social behavior, and "mobility range" (instrumental daily activities). Subscale scores and an overall score can be calculated from the number of confirmed sickness impact items. The SIP68 is a reliable instrument and a valid discriminative method able to detect changes in healthrelated functional status [41].

The DIP is a self-administered questionnaire concerning activities that may be restricted because of a disabling disease [43-44]. It consists of 39 questions about symptoms ( 3 items) and the five domains: mobility (10 items), self-care (6 items), social activities (10 items), communication (5 items), and psychological status (5 items). Every question is rated on a 0 - to 10 -point scale for the current level of disability (0: maximal disability, 10: no disability) and for the importance (impact) of that particular disability (0: not important at all, 10: most important of all). The validity of the DIP is satisfactory [44-45] and its reliability is acceptable [46].

Weighted scores are calculated by determining the deficit from the normal situation by subtracting the actual disability score from 10 and multiplying this deficit by the impact score for that item. This calculation results in a combined deficit score that is divided by 100 . This value is then subtracted from 1 . The result is a weighteditem score, combining aspects of the disability and the impact of this disability $[44,47]$.

The authors of the DIP defined a weighted score of $<0.50$ as a "major disruption of quality of life" [45]. However, because the COPM is not a norm-referenced measure, taking "major disruptions" as the starting point for comparison with the COPM was not feasible. Therefore, we chose a milder cutoff score; weighted scores $\leq 0.65$ are regarded as disruptions of quality of life [16].

The IPA measures self-perceived participation [4849]. The IPA, a self-administered generic questionnaire, assesses the impact of a condition on two different aspects of participation. One aspect is the perceived participation and autonomy for 31 items reflected in 5 domain scores (autonomy indoors, family role, autonomy outdoors, social relations, and work/education). The other aspect concerns the experienced problems related to aspects of participation, reflected in eight problem-experience scores. Perceived participation is scored on a 5-point rating scale, ranging from 1 (very good) to 5 (very poor). The perceived problems are scored on a 3-point rating scale ranging from 0 (no problem) to 2 (severe problem). For each domain, an overall score for the participation items is calculated, as well as one overall score for the eight problem-related experience items. The IPA is able to detect important within-person improvement over time, 
and its reliability and validity have been found to be good [48-49].

To investigate the client's opinion about the feasibility of the COPM, we developed two questionnaires to evaluate the client's perception of the COPM assessment and reassessment. The questionnaires consisted of a 9-item version for the initial COPM assessment and a short 4-item version for the COPM reassessment. The items concerned the goal, the method used to identify the perceived problems, the amount of time involved, and the COPM scores. For example, Was the aim of the interview clear to you? Was the interview an appropriate way to identify your problems? Was there enough time to tell your story? How did you experience rating the importance of your problems (was it easy/meaningful/annoying)? In the shorter reassessment version, the items about the identification of the perceived problems and the impact of scoring the importance of these problems were not included. The COPM experience could be rated as yes, partly, no, or no opinion.

\section{Procedure}

The clients were assessed twice. The assessors were blinded for the provided occupational therapy. The client and the occupational therapist planned the reassessment together 3 months after the first session or, if the therapy ended within 3 months, before the last occupational therapy session. A period of 3 months was chosen because we expected the occupational therapy to improve occupational performance by that time. The same assessor assessed each client twice, but because of difficulties in the planning, another assessor reassessed eight clients (6\%).

At the first assessment, we collected demographic information (i.e., age, diagnosis, duration of disease, sex, living situation, and cultural background) and conducted the COPM interview. At the reassessment, we asked the client to rate his/her performance and satisfaction with the prioritized problems identified during the first COPM interview. At first, we obtained scores without showing the client or the assessor the scores for that first assessment (blind scores). Later, we showed the clients their scores for the first assessment and asked them to rate their performance and satisfaction again (reflection scores).

After the first COPM assessment and the reassessment, clients completed the SIP68, DIP, IPA, and questionnaires about their opinion of the COPM assessment (9-item version) and the COPM reassessment (4-item version). After the reassessment, clients completed the tran- sition index. The treating occupational therapist received the information obtained by the COPM assessment.

\section{Data Analysis}

We assessed the responsiveness of the COPM performance and satisfaction scores by comparing the mean performance and the mean satisfaction scores of the first assessment with the mean scores of the reassessment, respectively. The data were analyzed in SPSS version 10.0 (SPSS, Inc; Chicago, Illinois).

\section{Criterion Responsiveness}

To establish to what extent the COPM is able to detect improvement over time (criterion responsiveness), we used the transition index as an external standard to measure the perception of change [37-38]. Improvement was defined as a rating of totally diminished, diminished, or slightly diminished for at least three of the five problems on the transition index. Because the perceived occupational performance problems prioritized on the COPM are often translated into therapeutic goals for improving the client's problems, the focus of this study of the COPM's responsiveness is on identifying improvement. Clients who indicated deterioration (slightly worse, worse, or much worse) for at least three of the five problems on the transition index were excluded from the analyses. We then used receiver operating characteristic (ROC) curves [32] to assess the responsiveness of the COPM. The ROC method is considered appropriate for evaluating if a measure is as good as its "gold standard" [32]. The ROC curve plots the sensitivity (true positive rate) versus 1 minus the specificity (false negative rate) for each possible cutoff point of the COPM change scores, based on the absence of improvement as defined by the transition index.

The area under the curve (AUC) for the ROC represents the probability that a client will be correctly identified by the COPM as improved. An AUC of 0.5 indicates that the COPM is a nondiscriminating test (not accurate), whereas an AUC of 1.0 implies perfect accuracy in distinguishing improved from unimproved [50]. We also used the ROC curve to select an optimum cutoff point, which reflects the COPM change score that provides the optimal distinction between improved and unimproved clients. This cutoff score is the optimal trade-off between sensitivity and specificity and is defined as the COPM change score for the data point closest to the upper left corner of the ROC curve. 


\section{Construct Responsiveness}

To study the relationship between the change in COPM scores and the change in SIP68, DIP, and IPA scores (construct responsiveness), we computed partial correlations between the reassessment scores for these measures, controlling for the scores for the initial assessment. Correlations were considered low $(<0.20)$, moderate (between 0.20 and 0.50 ), or high ( $>0.50)$ according to the recommendations of Cohen [51]. We performed a one-tailed significance test. Because the COPM focuses on activities, we expected correlations to be found on the SIP68, DIP, and IPA scales for activities but not for impairment or behavior.

\section{Feasibility and Correlations Between Performance and Satisfaction Scores}

We computed partial correlation coefficients (twotailed significance test) to assess the correlation between the mean COPM performance reassessment scores and the mean satisfaction reassessment scores, controlling for initial assessment scores. To study the differences between the performance and the satisfaction scores, we performed paired $t$-tests between the changes (difference between the initial assessment and reassessment) in the COPM mean performance and mean satisfaction scores. We performed descriptive analyses on the results of the questionnaires, assessing the client's perception of the feasibility of the COPM.

\section{RESULTS}

\section{Study Population}

Of the 243 clients invited to participate, 61 were unwilling and 30 were excluded because they did not ful- fill the inclusion criteria $(n=17)$ or could not be contacted $(n=9)$ ), or on the advice of a physician $(n=1)$ or because of planning problems $(n=3)$. In total, 152 clients were included, all of whom gave informed consent. All clients were referred to the occupational therapy in the usual way and can therefore be considered typical for occupational therapy at the participating institutions. After referral, the clients were checked only according to the inclusion criterion. No significant differences existed in age (50 \pm 15 , range $20-84$ vs $51 \pm 13$, range $25-83$ ) or sex (62\% female in both groups) between the participating and nonparticipating clients. The time interval between the first and the second assessment was $13 \pm 4$ (mean \pm standard deviation) weeks.

Incomplete data were obtained from 14 clients (first assessment $[n=7]$ and reassessment $[n=7]$ ) because of a worsening health condition $(n=3)$, termination of the occupational therapy sessions because of other priorities in the treatment $(n=3)$, death $(n=2)$, or nonresponse $(n=6)$. Complete data were obtained from 138 clients, and their characteristics are presented in Table 1.

Several issues were addressed in the COPM. In the self-care category, these included, for example, cleaning vegetables, pulling up the duvet while in bed, driving a car, getting in and out of the bath, and dressing. In the productivity category, these included, for example, walking up or down stairs while carrying materials, typing on the personal computer, visiting other companies, storing groceries, and looking after grandchildren. In the leisure category, these included, for example, playing the cello, playing outside with children, walking the dog, and other uncategorized examples such as using the telephone while lying in bed or moving again after a period of inactivity.

Table 1.

Characteristics of study population $(n=138)$. All values expressed in years.

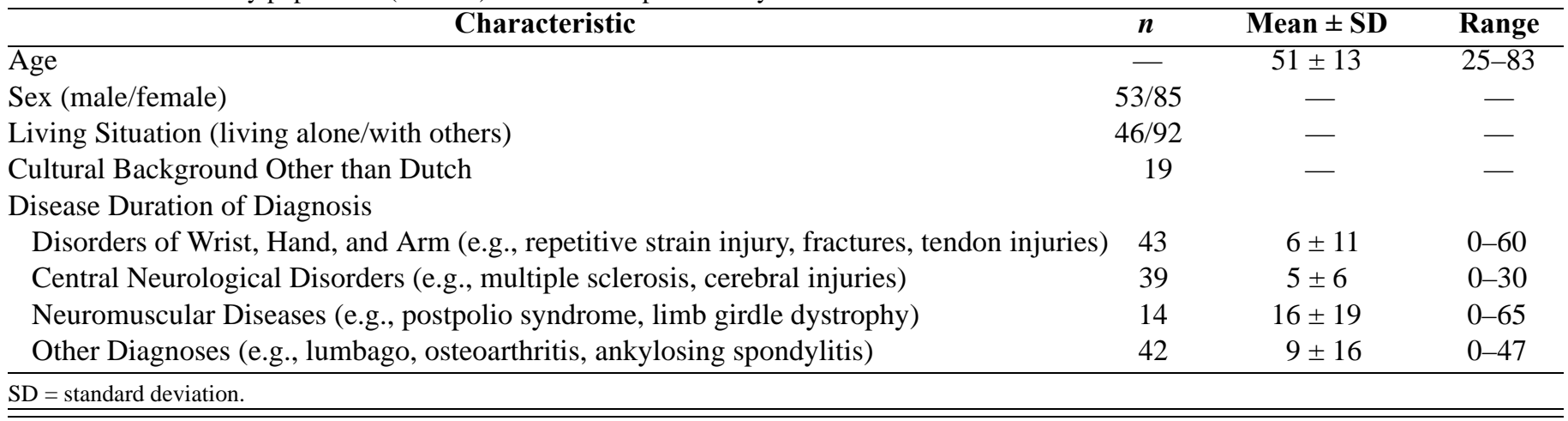




\section{Criterion Responsiveness}

We found significant differences between the mean COPM assessment and reassessment scores $(p<0.001)$. On the transition index, 78 of the 138 clients indicated an improvement (57\%), 40 clients indicated no change (29\%), and 20 clients (14\%) indicated deterioration. The clients indicating deterioration $(n=20)$ were excluded from the criterion responsiveness analyses. Table 2 shows the change scores for the mean COPM performance and satisfaction scores.

Table 2 also presents the AUCs and the cutoff values for improvement in the COPM performance and satisfaction scores. The AUCs were 0.79 (blind scores) and 0.85 (reflective scores). The optimal decision threshold (cutoff value) of the COPM for evaluating improvement perceived by the client ranged between 0.90 and 1.90 and was higher for the satisfaction scores than for the performance scores.

\section{Construct Responsiveness}

Most of the partial correlations between the COPM and the SIP68, DIP, and IPA were significant $(p<0.01)$ and positive but moderate (varying between 0.21 and 0.44 ) (Table 3). As expected, correlations between the COPM and the other measures were higher for the SIP68, DIP, and IPA subscales related to activities than for the subscales related to impairment and behavior. Low correlations were found for the SIP68 emotional stability subscale (e.g., impatience, anger) and the SIP68 psychological autonomy and communication subscale (e.g., concentration, problem-solving), the DIP communication subscale (e.g., hearing, talking, seeing), and the IPA social relations subscale (e.g., social intercourse, respect).

We found no significant correlation between the COPM and the SIP68 mobility control subscale. Fewer significant correlations existed between the COPM and the SIP68 than between the COPM and the DIP or the IPA (Table 3).

\section{Feasibility and Correlations Between Performance and Satisfaction Scores}

The partial correlation between the mean COPM performance and the satisfaction reassessment scores was $0.92(p<0.001)$. We found significant differences for the blind scores $(0.51 \pm 1.11)$, as well as for the reflection scores $(0.49 \pm 1.03)$, between the changes (reassessment minus the initial assessment) in the mean performance and the mean satisfaction scores $(p<0.001)$.

Clients' perceptions of the COPM assessment and reassessment are presented in Table 4. At the initial assessment, more than 90 percent of the clients indicated that the purpose of the COPM interview was clear and that the COPM was a good way to identify the perceived problems. At the first assessment, 22.8 percent of the clients indicated that it was easy to give scores for importance and 25.9 percent indicated that it was easy to give scores for performance and satisfaction. Approximately 80 percent indicated that it was meaningful, and 5 percent of the clients indicated that it was annoying to give scores. At the reassessment, the number of clients who indicated that it was easy to give performance and satisfaction scores increased significantly from 25.9 to 46.4 percent $(p<0.001)$.

\section{DISCUSSION}

This study focused on the responsiveness of the COPM. The criterion responsiveness of the COPM indicated good discriminatory power of the COPM to detect improvement from no improvement. The authors of the COPM manual noticed that, because the COPM is an individualized measure, the meaning of the change scores

Table 2.2

Change scores and responsiveness of the Canadian Occupational Performance Measure (COPM) (area under curve [AUC] and optimal cutoff value) $(n=118)$.

\begin{tabular}{|c|c|c|c|c|}
\hline \multirow[b]{2}{*}{ Value } & \multicolumn{2}{|c|}{ COPM Performance } & \multicolumn{2}{|c|}{ COPM Satisfaction } \\
\hline & Blind & Reflection & Blind & Reflection \\
\hline Change Score & $1.61 \pm 1.77-2.00-6.20$ & $1.61 \pm 1.70-1.80-6.20$ & $2.13 \pm 2.03-1.60-8.50$ & $2.08 \pm 2.00-1.80-8.50$ \\
\hline Optimal Cutoff Value & 1.37 & 0.90 & 1.90 & 1.45 \\
\hline
\end{tabular}


Table 3.3

Partial correlations between the Canadian Occupational Performance Measure (COPM) reassessment scores and reassessment scores of, respectively, categories of SIP68, DIP, and IPA questionnaires, controlling for effect of initial assessment scores (one-tailed significance test).

\begin{tabular}{|c|c|c|c|c|}
\hline \multirow{2}{*}{ Questionnaire } & \multicolumn{2}{|c|}{ COPM Performance } & \multicolumn{2}{|c|}{ COPM Satisfaction } \\
\hline & Blind & Reflection & Blind & Reflection \\
\hline \multicolumn{5}{|l|}{ SIP68 Category } \\
\hline Somatic Autonomy & $0.2090^{*}$ & $0.2292^{*}$ & $0.1677^{\dagger}$ & $0.1600^{\dagger}$ \\
\hline Mobility Control & 0.0164 & 0.0020 & 0.0322 & 0.0167 \\
\hline Social Behavior & $0.2150^{*}$ & $0.2143^{*}$ & $0.2359^{*}$ & $0.2106^{*}$ \\
\hline Emotional Stability & 0.0246 & 0.0326 & 0.0970 & 0.0880 \\
\hline Mobility Range & $0.4043^{*}$ & $0.4072^{*}$ & $0.3566^{*}$ & $0.3402^{*}$ \\
\hline Psychological Autonomy and Communication & 0.0019 & 0.0059 & 0.0155 & 0.0056 \\
\hline \multicolumn{5}{|l|}{ DIP Category } \\
\hline Symptology & 0.1412 & $0.1876^{\dagger}$ & $0.2266^{*}$ & $0.2213^{*}$ \\
\hline Mobility & $0.3983^{*}$ & $0.4200^{*}$ & $0.4240^{*}$ & $0.4362^{*}$ \\
\hline Self-Care & $0.2725^{*}$ & $0.2789^{*}$ & $0.3026^{*}$ & $0.3015^{*}$ \\
\hline Social Activities & $0.2308^{*}$ & $0.2109^{*}$ & $0.2420^{*}$ & $0.2431^{*}$ \\
\hline Communication & 0.1383 & 0.1417 & 0.1420 & $0.1473^{\dagger}$ \\
\hline Psychosocial Status & $0.2137^{*}$ & $0.2506^{*}$ & $0.2653^{*}$ & $0.3092^{*}$ \\
\hline \multicolumn{5}{|l|}{ IPA Category } \\
\hline Autonomy Indoors & $0.3463^{*}$ & $0.3221^{*}$ & $0.3853^{*}$ & $0.3671^{*}$ \\
\hline Family Role & $0.3646^{*}$ & $0.3490^{*}$ & $0.4100^{*}$ & $0.3987^{*}$ \\
\hline Autonomy Outdoors & $0.3656^{*}$ & $0.3485^{*}$ & $0.4048^{*}$ & $0.3917^{*}$ \\
\hline Social Relations & $0.1498^{\dagger}$ & 0.1290 & $0.2218^{*}$ & $0.2102^{*}$ \\
\hline Work and Education & $0.2693^{*}$ & $0.2447^{*}$ & $0.3194^{*}$ & $0.2954^{*}$ \\
\hline Total (Problem-Related Experience) & $0.3141^{*}$ & $0.3121^{*}$ & $0.3949^{*}$ & $0.3806^{*}$ \\
\hline
\end{tabular}

Table 4.4

Clients' perceptions of the Canadian Occupational Performance Measure (COPM) assessment and reassessment (\%) $(n=138)$.

\begin{tabular}{|c|c|c|c|c|c|c|c|c|}
\hline \multirow[b]{2}{*}{ Variable } & \multicolumn{4}{|c|}{ Assessment COPM } & \multicolumn{4}{|c|}{ Reassessment COPM } \\
\hline & Yes & Partly & No & $\begin{array}{c}\text { No } \\
\text { Opinion }\end{array}$ & Yes & Partly & No & $\begin{array}{c}\text { No } \\
\text { Opinion }\end{array}$ \\
\hline Clear Purpose & 98.6 & 1.4 & - & - & 96.4 & 2.9 & 0.7 & - \\
\hline Good Method to Identify Problems & 92.8 & 7.2 & - & - & - & - & - & - \\
\hline Sufficient Space/Time & 97.8 & 2.2 & - & - & - & - & - & - \\
\hline \multicolumn{9}{|l|}{ Giving Scores for Importance } \\
\hline Easy & 22.8 & 49.3 & 27.9 & - & - & - & - & - \\
\hline Meaningful & 80.0 & 17.0 & 1.5 & 1.5 & - & - & - & - \\
\hline Annoying & 4.5 & 13.4 & 79.9 & 2.2 & - & - & - & - \\
\hline \multicolumn{9}{|c|}{ Giving Scores for Performance and Satisfaction } \\
\hline Easy & 25.9 & 40.0 & 34.1 & - & 46.4 & 36.2 & 15.9 & 1.4 \\
\hline Meaningful & 81.6 & 14.0 & 2.2 & 2.2 & 79.7 & 14.5 & 2.2 & 3.6 \\
\hline Annoying & 5.3 & 12.0 & 81.2 & 1.5 & 2.9 & 7.2 & 87.7 & 2.2 \\
\hline
\end{tabular}


may vary for each individual, but when the COPM is used for research, setting a change level (cutoff value) a priori is best [52]. Results of the criterion responsiveness in our study showed optimum decision thresholds (cutoffs) between clients who improved and clients who did not improve. These cutoff values were lower than the 2-point difference indicated in the COPM manual as clinically important [7].

We used an external standard, a transition index, to establish the criterion responsiveness. However, the use of such indexes can be questionable because their reliability and validity are difficult to verify and because the assessment of change is psychologically difficult, as a subtraction has to be made from the present and the initial state [53]. A solution for this dilemma is to show patients their previous scores [49]. Despite some disadvantages, transition indexes are useful alternatives when a treatment of known efficacy is missing [49]. They have proven to be useful external standards against which to compare change scores on health status measures [54]. In the present study, the COPM and the transition index were both used to evaluate the client's perceived problems. The results showed that the measured changes reflected what the client considered to be a relevant change.

The construct responsiveness of the COPM was also supported in this study, because the change scores on the COPM showed significant correlations with the domains of other instruments (SIP68, DIP, and IPA) related to activities and not on the domains related to impairment and to social and emotional behavior. The absence of significant correlations can occur because, in many disorders, no clear relationship exists between impairments and either performance or problem-related experience $[7,55]$.

The significant correlations were moderate, probably because the COPM offers significant individual variance [16] because the COPM incorporates the individual client perspectives, expectations, and preferences in an outcome measure. With scoring systems that are based on individualized measures, the clients assess themselves. This method of measurement seems to show an improved sensitivity to change in health-related functional status compared with conventional methods that are less focused on the integration of individual patient perspectives [28].

The lower correlations between the COPM and the subscales of the SIP68 than between the COPM and both the DIP and the IPA can be explained because the SIP68 provides no information about the distinction between the inability to perform an activity and the perception that this is a problem.

The COPM reassessment scores can be obtained with [56] and without [7] showing clients the results of the initial assessment (reflective scoring and blind scoring). The results of our study supported the responsiveness of both types of scoring. However, the results also showed that the discriminatory power of the COPM to detect improvement was lower for the blind scores than for the reflection scores. The cutoff values for the reflection scores were also lower than for the blind scores. These results demonstrate that when the COPM is used for evaluation over time, results will be interpreted differently if the initial scores are shown prior to the reassessment. If one's primary interest is to detect changes over time, showing clients the scores of their initial assessment during the reassessment appears to help avoid problems in remembering the value of the activity as scored at the initial assessment. If one's primary interest is to detect the current perception, then showing clients their previous scores does not appear advisable [52].

The performance and satisfaction scores of the COPM in the present study were highly correlated. Significant correlations have also been found in other studies for the changes in scores $[17,22,56]$ and for the scores at the initial assessment and at the reassessment $[23,26]$. A possible reason for the significant correlations is that clients have difficulty interpreting the difference between the concepts of performance and satisfaction. If these two concepts are measuring the same feature, the necessity of using scores for both performance and satisfaction is questionable.

The results of our study also demonstrated that the change scores for satisfaction were 0.5 higher than the change scores for performance. These results are supported by Persson et al., who found in a study focusing on a pain management program that the improvement in satisfaction seemed to be greater than the actual change in occupational performance [23]. Most likely, a reevaluation of occupational performance took place [23]. An increase in satisfaction might reflect the process of adopting new skills and coping strategies and more adequate acceptance of an altered life situation [23]. By talking to the client about the differences between the performance and satisfaction scores, one can obtain important information about this process of reevaluation. Further research is needed to determine the necessity of using both scores, i.e., the performance score and the satisfaction score. 
Finally, we asked the clients about their experiences with the COPM. Several studies indicated that the use of scales for scoring may be abstract and difficult for some clients $[13,21]$. Although we also found that scoring was difficult for many clients during the first COPM assessment, clients also said they thought that the COPM was a good way to identify their problems. Also, during the reassessment, the number of clients who found the scoring easy increased significantly. Possible reasons are that clients find it easier to rate their problems with performance and their satisfaction when they have used the rating scales before or when more attention is paid to their problems during the intervention.

\section{LIMITATIONS}

In the present study, we chose to use a generic population and generic interventions to establish the responsiveness of the COPM. However, looking for differences in cutoff points for specific diagnostic groups, specific interventions, and different disease stadia or disease duration would also be interesting.

Also, in this study we focused on the capability of the COPM to detect change in time but we do not know whether the therapeutic goals were directed toward the issues reported on the COPM. The results of the COPM assessment were given to the occupational therapists to use these for therapeutic purposes, but the occupational therapists were free in their choice to use this information.

In our analysis, we also focused on improvement in time because we assumed that mostly the prioritized problems on the COPM are translated into therapeutic goals. Because we have not checked this assumption, one can question whether excluding the deteriorated patients was a good decision. Also interesting to know would be whether clients are deteriorated in time, e.g., because no therapy was provided or because the clients suffer from a progressive disease.

\section{CONCLUSIONS}

Despite these limitations, our study has demonstrated that the COPM is an individualized, client-centered outcome measure that is sensitive to changes in the occupational performance and satisfaction of the client's most important problems in daily functioning. These changes over time were in accordance with the changes detected by other measurement instruments. Since both the construct and the criterion responsiveness of the COPM are supported by the results of this study, we conclude that the changes in the COPM scores appeared to validly represent the occupational performance of the client over time.

\section{ACKNOWLEDGMENTS}

\section{Author Contributions:}

Study concept and design: I. C. J. M. Eyssen, M. P. M. Steultjens, J. Dekker.

Acquisition of data: I. C. J. M. Eyssen, T. A. M. Oud, E. M. Bolt, A. Maasdam.

Analysis and interpretation of data: I. C. J. M. Eyssen, M. P. M. Steultjens, T. A. M. Oud, J. Dekker.

Drafting of manuscript: I. C. J. M. Eyssen, T. A. M. Oud. Critical revision of manuscript for important intellectual content:

I. C. J. M. Eyssen, T. A. M. Oud, E. M. Bolt, A. Maasdam, J. Dekker, M. P. M. Steultjens.

Statistical analysis: I. C. J. M. Eyssen, M. P. M. Steultjens.

Study supervision: J. Dekker.

Financial Disclosures: The authors have declared that no competing interests exist.

Funding/Support: This material was based on work supported by ZonMw, The Netherlands Organisation for Health Research and Development, grant 1310.0005 .

Institutional Review: The local ethics committees of the VU University Medical Centre and the Academic Medical Centre in Amsterdam, the Netherlands, approved this study, and the authors obtained informed consent from all participating patients.

Participant Follow-Up: The authors have sent an information sheet to all participants with general information about the research and with the invitation to contact them for publications about the results of this study.

\section{REFERENCES}

1. Health topics: Rehabilitation [Internet]. Geneva (Switzerland): World Health Organization; 2010. Available from: http://www.who.int/topics/rehabilitation/en/.

2. Carpenter L, Baker GA, Tyldesley B. The use of the Canadian occupational performance measure as an outcome of a pain management program. Can J Occup Ther. 2001;68(1): 16-22. [PMID: 11233684]

3. Wressle E, Samuelsson K, Henriksson C. Responsiveness of the Swedish version of the Canadian Occupational Performance Measure. Scand J Occup Ther. 1999;6(2):84-89. DOI:10.1080/110381299443771

4. Townsend E, Sue Stanton; Canadian Association of Occupational Therapists. Enabling occupation: An occupational therapy perspective. Ottawa (Canada): Canadian Association of Occupational Therapists; 2002. 
5. Carson R. Are you listening? Client-centred practice in an American acute care rehabilitation hospital: a case study. Occup Ther Now. 1999;1(3):5-7 [cited 2011 Mar 22]. Available from: http://www.caot.ca/otnow/may99-eng/ may99-client.cfm/

6. Riemsma RP, Forbes CA, Glanville JM, Eastwood AJ, Kleijnen J. General health status measures for people with cognitive impairment: Learning disability and acquired brain injury. Health Technol Assess. 2001;5(6):1-100. [PMID: 11319989]

7. Law M, Baptiste S, Carswell A, McColl MA, Polatajko H, Pollock N. Canadian Occupational Performance Measure. 4th ed. Toronto (Canada): Canadian Association of Occupational Therapists; 2005.

8. Townsend EA, Polatjako HJ. Enabling occupation II: Advancing an occupational therapy vision for health, wellbeing \& justice through occupation. Ottawa (Canada): Canadian Association of Occupational Therapists; 2007.

9. Cup EH, Scholte op Reimer WJ, Thijssen MC, Kuyk-Minis MA. Reliability and validity of the Canadian Occupational Performance Measure in stroke patients. Clin Rehabil. 2003;17(4):402-9. [PMID: 12785249$]$

DOI:10.1191/0269215503cr635oa

10. Eyssen IC, Beelen A, Dedding C, Cardol M, Dekker J. The reproducibility of the Canadian Occupational Performance Measure. Clin Rehabil. 2005;19(8):888-94.

[PMID: 16323388] DOI:10.1191/0269215505cr883oa

11. Pan AW, Chung L, Hsin-Hwei G. Reliability and validity of the Canadian Occupational Performance Measure for clients with psychiatric disorders in Taiwan. Occup Ther Int. 2003;10(4):269-77. [PMID: 14647540] DOI:10.1002/oti.190

12. Sewell L, Singh SJ. The Canadian Occupational Performance Measure: Is it a reliable measure in clients with chronic obstructive pulmonary disease? $\mathrm{Br} \mathrm{J}$ Occup Ther. 2001; 64(6):305-10.

13. Carswell A, McColl MA, Baptiste S, Law M, Polatajko H, Pollock N. The Canadian Occupational Performance Measure: A research and clinical literature review. Can J Occup Ther. 2004;71(4):210-22. [PMID: 15586853]

14. Bodiam C. The use of the Canadian Occupational Performance Measure for the assessment of outcome on a neurorehabilitation unit. Br J Occup Ther. 1999;62(3):123-26.

15. Chan CC, Lee TM. Validity of the Canadian Occupational Performance Measure. Occup Ther Int. 1997;4(3):229-47. DOI:10.1002/oti.58

16. Dedding C, Cardol M, Eyssen IC, Dekker J, Beelen A. Validity of the Canadian Occupational Performance Measure: A client-centred outcome measurement. Clin Rehabil. 2004;18(6):660-67. [PMID: 15473118]

DOI:10.1191/0269215504cr746oa
17. McColl MA, Paterson M, Davies D, Doubt L, Law M. Validity and community utility of the Canadian Occupational Performance Measure. Can J Occup Ther. 2000; 67(1):22-30. [PMID: 10695166]

18. Verkerk GJ, Wolf MJ, Louwers AM, Meester-Delver A, Nollet F. The reproducibility and validity of the Canadian Occupational Performance Measure in parents of children with disabilities. Clin Rehabil. 2006;20(11):980-88.

[PMID: 17065541]

DOI:10.1177/0269215506070703

19. Chenq YH, Rodger S, Polatjko H. Experiences with the COPM and client-centred practice in adult neurorehabilitation in Taiwan. Occup Ther Int. 2002;9(3):167-84.

[PMID: 12921096]

DOI:10.1002/oti.163

20. Donnelly C, Eng JJ, Hall J, Alford L, Giachino R, Norton $\mathrm{K}$, Kerr DS. Client-centred assessment and the identification of meaningful treatment goals for individuals with a spinal cord injury. Spinal Cord. 2004;42(5):302-7.

[PMID: 14993893]

DOI:10.1038/sj.sc.3101589

21. Donnelly C, Carswell A. Individualized outcome measures: A review of the literature. Can J Occup Ther. 2002; 69(2):84-94. [PMID: 11977872]

22. Law M, Polatjko H, Pollock N, McColl MA, Carswell A, Baptiste S. Pilot testing of the Canadian Occupational Performance Measure: Clinical and measurement issues. Can J Occup Ther. 1994;61(4):191-97. [PMID: 10137673]

23. Persson E, Rivano-Fischer M, Eklund M. Evaluation of changes in occupational performance among patients in a pain management program. J Rehabil Med. 2004;36(2):85-91. [PMID: 15180223] DOI:10.1080/16501970310019142

24. Samuelsson KA, Tropp H, Gerdle B. Shoulder pain and its consequences in paraplegic spinal cord-injured, wheelchair users. Spinal Cord. 2004;42(1):41-46. [PMID: 14713943] DOI:10.1038/sj.sc.3101490

25. Wressle E, Marcusson J, Henriksson C. Clinical utility of the Canadian Occupational Performance Measure-Swedish version. Can J Occup Ther. 2002;69(1):40-48. [PMID: 11852689]

26. Wressle E, Lindstrand J, Neher M, Marcusson J, Henriksson C. The Canadian Occupational Performance Measure as an outcome measure and team tool in a day treatment programme. Disabil Rehabil. 2003;25(10):497-506. [PMID: 12745961] DOI:10.1080/0963828031000090560

27. Guyatt GH, Kirshner B, Jaeschke R. Measuring health status: What are the necessary measurement properties? J Clin Epidemiol. 1992;45(12):1341-45. [PMID: 1460470] DOI:10.1016/0895-4356(92)90194-R 
28. Middel B, Van Sonderen E. Statistical significant change versus relevant or important change in (quasi) experimental design: Some conceptual and methodological problems in estimating magnitude of intervention-related change in health services research. Int J Integr Care. 2002;2:e15. [PMID: 16896390]

29. Mokkink LB, Terwee CB, Patrick DL, Alonso J, Stratford PW, Knol DL, Bouter LM, De Vet HC. The COSMIN study reached international consensus on taxonomy, terminology, and definitions of measurement properties for healthrelated patient-reported outcomes. J Clin Epidemiol. 2010; 63(7):737-45. [PMID: 20494804]

DOI:10.1016/j.jclinepi.2010.02.006

30. Bot SD, Terwee CB, Van der Windt DA, Bouter LM, Dekker J, De Vet HC. Clinimetric evaluation of shoulder disability questionnaires: A systematic review of the literature. Ann Rheum Dis. 2004;63(4):335-41. [PMID: 15020324] DOI:10.1136/ard.2003.007724

31. Terwee CB, Dekker FW, Wiersinga WM, Prummel MF, Bossuyt PM. On assessing responsiveness of health-related quality of life instruments: Guidelines for instrument evaluation. Qual Life Res. 2003;12(4):349-62. [PMID: 12797708$]$ DOI:10.1023/A:1023499322593

32. Mokkink LB, Terwee CB, Patrick DL, Alonso J, Stratford PW, Knol DL, Bouter LM, De Vet HC. The COSMIN checklist for assessing the methodological quality of studies on measurement properties of health status measurement instruments: An international Delphi study. Qual Life Res. 2010;19(4):539-49. [PMID: 20169472]

DOI:10.1007/s11136-010-9606-8

33. Mokkink LB, Terwee CB, Knol DL, Stratford PW, Alonso J, Patrick DL, Bouter LM, De Vet HC. The COSMIN checklist for evaluating the methodological quality of studies on measurement properties: A clarification of its content. BMC Med Res Methodol. 2010;10:22.

[PMID: 20298572]

DOI:10.1186/1471-2288-10-22

34. Effing E, Dirx E, Sleegers EJ, Van Meeteren N. De responsiviteit van de COPM, ARA en SODA voor veranderingen in handvaardigheid bij plastisch-chirurgische handpatienten [The responsiveness of the COPM, ARA, and SODA to detect changes in hand skills of patients after plastic surgery.] Nederlands Tijdschrift voor Ergotherapie. 1999;27(3):109-16 [cited 2011 Mar 22]. Available from: http://www.boomlemma.nl/

35. Case-Smith J. Outcomes in hand rehabilitation using occupational therapy services. Am J Occup Ther. 2003;57(5): 499-506. [PMID: 14527111]

DOI:10.5014/ajot.57.5.499

36. Van Duijn HM, Niezen AA, Cardol M, Corder-Bartels IE, Verkerk GJQ. Canadees meetinstrument voor handelingen en vaardigheden [Canadian Occupational Performance
Measure (COPM)—Dutch version]. Amsterdam (the Netherlands): AMC/VU University Medical Centre; 1999.

37. Husted JA, Cook RJ, Farewell VT, Gladman DD. Methods for assessing responsiveness: A critical review and recommendations. J Clin Epidemiol. 2000;53(5):459-68.

[PMID: 10812317]

DOI:10.1016/S0895-4356(99)00206-1

38. Fitzpatrick R, Ziebland S, Jenkinson C, Mowat A, Mowat A. Transition questions to assess outcomes in rheumatoid arthritis. Br J Rheumatol. 1993;32(9):807-11. [PMID: 8369891] DOI:10.1093/rheumatology/32.9.807

39. Haywood KL, Garratt AM, Jordan K, Dziedzic K, Dawes PT. Disease-specific, patient-assessed measures of health outcome in ankylosing spondylitis: Reliability, validity and responsiveness. Rheumatology (Oxford). 2002;41(11):1295-302.

[PMID: 12422003]

DOI:10.1093/rheumatology/41.11.1295

40. World Health Organization. International classification of functioning, disability and health: ICF. Geneva (Switzerland): World Health Organization; 2001.

41. De Bruin AF, Diederiks JP, De Witte LP, Stevens FC, Philipsen $\mathrm{H}$. Assessing the responsiveness of a functional status measure: The Sickness Impact Profile versus the SIP68. J Clin Epidemiol. 1997;50(5):529-40. [PMID: 9180645] DOI:10.1016/S0895-4356(97)00047-4

42. Nanda U, McLendon PM, Andresen EM, Armbrecht E. The SIP68: An abbreviated sickness impact profile for disability outcomes research. Qual Life Res. 2003;12(5):583-95.

[PMID: 13677503]

DOI:10.1023/A:1025036325886

43. Cohen L, Pouwer F, Pfennings LE, Lankhorst GJ, Van der Ploeg HM, Polman CH, Adèr HJ, Jønnson A, Vleugels L. Factor structure of the Disability and Impact Profile in patients with multiple sclerosis. Qual Life Res. 1999;8(1-2):141-50. [PMID: 10457747] DOI:10.1023/A:1026481029191

44. Lankhorst GJ, Jelles F, Smits RC, Polman CH, Kuik DJ, Pfennings LE, Cohen L, Van der Ploeg HM, Ketelaer P, Vleugels L. Quality of life in multiple sclerosis: The disability and impact profile (DIP). J Neurol. 1996;243(6): 469-74. [PMID: 8803821] DOI:10.1007/BF00900502

45. Pfennings LE, Van der Ploeg HM, Cohen L, Bramsen I, Polman CH, Lankhorst GJ, Vleugels L. A health-related quality of life questionnaire for multiple sclerosis patients. Acta Neurol Scand. 1999;100(3):148-55. [PMID: 10478577] DOI:10.1111/j.1600-0404.1999.tb00730.x

46. Pfennings L, Cohen L, Van der Ploeg H, Polman C, Lankhorst G. Reliability of two measures of health-related quality of life in patients with multiple sclerosis. Percept Mot Skills. 1998;87(1):111-14. [PMID: 9760635] 
47. Laman H, Lankhorst GJ. Subjective weighting of disability: An approach to quality of life assessment in rehabilitation. Disabil Rehabil. 1994;16(4):198-204.

[PMID: 7812020]

DOI:10.3109/09638289409166613

48. Cardol M, De Haan RJ, De Jong BA, Van den Bos GA, De Groot IJ. Psychometric properties of the Impact on Participation and Autonomy Questionnaire. Arch Phys Med Rehabil. 2001;82(2):210-16. [PMID: 11239312] DOI:10.1053/apmr.2001.18218

49. Cardol M, Beelen A, Van den Bos GA, De Jong BA, De Groot IJ, De Haan RJ. Responsiveness of the Impact on Participation and Autonomy questionnaire. Arch Phys Med Rehabil. 2002;83(11):1524-29. [PMID: 12422319] DOI:10.1053/apmr.2002.35099

50. Streiner DL, Norman GR. Health measurement scales: A practical guide to their development and use. 2nd ed. Oxford (UK): Oxford University Press; 1995.

51. Cohen J. Statistical power analysis for the behavioral sciences. New York (NY): Academic; 1969.

52. Law M, Baptiste S, Carswell A, McColl M, Polatajko H, Pollock N. COPM: Questions and answers [Internet]. Updated 2004 Mar 27. Available from: www.caot.ca/copm/ questions.html.

53. Norman GR, Stratford P, Regehr G. Methodological problems in the retrospective computation of responsiveness to change: The lesson of Cronbach. J Clin Epidemiol. 1997; 50(8):869-79. [PMID: 9291871] DOI:10.1016/S0895-4356(97)00097-8
54. Deyo RA, Inui TS. Toward clinical applications of health status measures: Sensitivity of scales to clinically important changes. Health Serv Res. 1984;19(3):275-89. [PMID: 6746293]

55. Badley EM. An introduction to the concepts and classifications of the International Classification of Impairments, Disabilities, and Handicaps. Disabil Rehabil. 1993;15(4): 161-78. [PMID: 8219245] DOI:10.3109/09638289309166008

56. Walsh DA, Kelly SJ, Johnson PS, Rajkumar S, Bennetts K. Performance problems of patients with chronic low-back pain and the measurement of patient-centered outcome. Spine. 2004;29(1):87-93. [PMID: 14699282] DOI:10.1097/01.BRS.0000105533.09601.4F

Submitted for publication June 3, 2010. Accepted in revised form November 22, 2010.

This article and any supplementary material should be cited as follows:

Eyssen ICJM, Steultjens MPM, Oud TAM, Bolt EM, Maasdam A, Dekker J. Responsiveness of the Canadian Occupational Performance Measure. J Rehabil Res Dev. 2011;48(5):517-28.

DOI:10.1682/JRRD.2010.06.0110

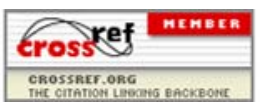




\title{
Responsiveness of the Canadian Occupational Performance Measure
}

\author{
Isaline C. J. M. Eyssen, MSc, OT; ${ }^{*}$ Martijn P. M. Steultjens, PhD ${ }^{2}$ Tanja A. M. Oud, OT; ${ }^{3}$ E. Marije Bolt, \\ OT; ${ }^{3}$ Anke Maasdam, OT; ${ }^{1}{\text { Joost Dekker, } \text { PhD }^{1,4}}^{1,4}$ \\ ${ }^{1}$ Department of Rehabilitation Medicine, VU (Vrije Universiteit) University Medical Centre, Amsterdam, the Nether- \\ lands; ${ }^{2}$ School of Health, Glasgow Caledonian University, Glasgow, Scotland; ${ }^{3}$ Department of Rehabilitation, Aca- \\ demic Medical Centre, Amsterdam, the Netherlands; ${ }^{4}$ EMGO (Extramuraal Geneeskundig Onderzoek) Institute for \\ Health and Care Research and Department of Psychiatry, VU University Medical Centre, Amsterdam, the Netherlands
}

\begin{abstract}
This study evaluated the responsiveness of the Canadian Occupational Performance Measure (COPM), an individualized, client-centered outcome measure for the identification and evaluation of self-perceived occupational performance problems. We recruited 152 consecutive patients with various diagnoses, admitted to the outpatient clinic of two occupational therapy departments, to complete a COPM interview and three self-reported health status questionnaires on two occasions: prior to the start of occupational therapy treatment and 3 months later. The three questionnaires were the Sickness Impact Profile (SIP68), the Disability and Impact Profile (DIP), and the Impact on Participation and Autonomy (IPA). We assessed criterion responsiveness by calculating the area under the curve (AUC) for the receiver operating characteristic curve and the optimal cutoff values for the COPM scores. To determine construct responsiveness, we calculated correlations between the change in COPM scores and the change in the SIP68, DIP, and IPA scores. The AUC ranged from 0.79 to 0.85 , and the optimal cut-off values for the performance scores and satisfaction scores ranged from 0.9 to 1.9. We found significant positive correlations between the COPM scores and the SIP68, DIP, and IPA scores. The capability of the COPM to detect changes in perceived occupational performance issues is supported.
\end{abstract}

Key words: client-centered, COPM, needs assessment, occupational therapy, outcome assessment, patient participation, patient satisfaction, psychometrics, rehabilitation, treatment outcome.

\section{INTRODUCTION}

In rehabilitation, reducing disabilities and attaining independence and self-determination are important goals [1]. Assessment should therefore focus on disabilities and various aspects of occupational performance [2-3]. Occupational performance can be defined as the ability to choose, organize, and satisfactorily perform meaningful actions that are needed to look after oneself, enjoy life, and contribute to the social and economic fabric of a community [4]. This implies that not all clients need to share the same definition of enhanced occupational performance [5] and that not all clients with the same clinical status have the same goals or responses to treatment. Although many physiological measures provide clinicians with information, they often correlate poorly with functional capacity and well-being, the areas that are most important for clients [6]. A client-centered evalua-

\footnotetext{
Abbreviations: AUC $=$ area under the curve, $\mathrm{COPM}=$ Canadian Occupational Performance Measure, DIP = Disability and Impact Profile, IPA = Impact on Participation and Autonomy, ROC $=$ receiver operating characteristic, SIP68 $=$ Sickness Impact Profile, VU = Vrije Universiteit.

${ }^{*}$ Address all correspondence to Isaline C. J. M. Eyssen, MSc, OT; VU University Medic al Centre, Department of Rehabilitation Medicine/Occupational Therapy, PO Box 7057, 1007 MB Amsterdam, the Netherl ands; +31-204440012; fax: +31-20-4440006. Email: i.evssen@vumc.nl DOI:10.1682/JRRD.2010.06.0110
} 
tion of occupational performance, i.e., with the Canadian Occupational Performance Measure (COPM) [7], can help account for individual changes.

The COPM is an outcome measure designed to help clients identify, prioritize, and evaluate important issues they encounter in occupational performance [7]. This individualized outcome measure is used to assess a client's self-perception of actual performance and satisfaction with this performance over time. The assessment is conducted with a semistructured interview format and a structured scoring method and aims to assess change in a client's self-perception in occupational performance over time [7]. The conceptual basis of the COPM is derived from the Canadian Model of Occupational Performance, which is now extended to the Canadian Model of Occupational Performance and Engagement [4,7-8].

The clinimetric properties of the COPM have been studied in various situations. The reproducibility of the performance and satisfaction scores was found to be poor for the individually identified problems and moderate to high for the scores averaged over all the problems identified by a client [7,9-13]. Supportive evidence was found for the content, convergent, and divergent validities of the COPM [2,7,9,11,13-18]. Clinical utility, evaluated in a number of different studies, supported the use of the COPM for a variety of clients in different settings $[13,17,19-26]$. The COPM is designed to not only identify the client's perceived problems but also determine whether these problems have changed over time. The capability of a measure to detect change over time is referred to as its responsiveness [27-28].

The difference between validity and responsiveness is that validity refers to the validity of a single score and responsiveness refers to the validity of a change score [29]. As a logical consequence, criterion and construct responsiveness can be defined analogous to criterion and construct validity [29]. Criterion responsiveness is defined as the extent to which change in scores on a particular instrument relates to change in the gold standard. Construct responsiveness is defined as the extent to which change in scores on a particular instrument relates to change in other measures.

Various approaches exist for measuring responsiveness [28-32]. Inappropriate measures of responsiveness are the use of effect sizes and related measures such as standardized response mean and relative efficacy statistics [33]. A suitable method to assess responsiveness is calculating change scores for clients whose health is expected to have changed and to examine the correlation with corresponding changes in a reference measure or transition indices [30-32].

Several studies have indicated that the COPM is sensitive to change [2-3,7,12-13,20,34-35]. However, some of these studies are unpublished [7], used no criterion standard [3,7], or focused on a small study population [12,34] or specific diagnoses [20,34-35]. Therefore, the responsiveness of the COPM needs to be further evaluated.

The main objective of the present study was to evaluate the responsiveness of the COPM in a population of outpatients receiving occupational therapy interventions. Our evaluation was based on two research questions:

1. To what extent is the COPM able to detect improvement over time (criterion responsiveness)?

2. To what extent do changes in the COPM correlate with changes in other measures (construct responsiveness)?

Additionally, we evaluated the feasibility of the COPM and the correlation between the satisfaction and performance scores of the COPM.

\section{METHODS}

\section{Study Population and Assessors}

We recruited consecutive clients with various conditions who were newly referred to the outpatient occupational therapy departments of the Academic Medical Centre and the VU (Vrije Universiteit) University Medical Centre in Amsterdam. All clients received oral and written information about the study. Our intent was to include 150 clients, 75 in each center.

Inclusion criteria were 18 years or older, perceived limitations in more than one activity of daily living, and an outpatient treatment indication for occupational therapy. Clients who were currently receiving occupational therapy or had insufficient understanding of the Dutch language were excluded. Written informed consent was obtained from all participants.

Four assessors, two in each hospital, collected the data. They were all occupational therapists trained in administering the COPM. The assessors were not involved in the therapy sessions; the assessments were performed independently from the provided occupational therapy.

\section{Instruments}

The official Dutch translation of the COPM was used [36]. With the COPM, the therapist helps the client identify 
activities that the client "wants, needs, or is expected to perform" [7] and in which the client experiences problems with the actual performance or is dissatisfied with the level of performance. Accordingly, the client prioritizes up to five problems that are the most urgent or important and rates each of these problems on an ordinal 10-point scale regarding performance (where $1=$ "not able to do it at all" and $10=$ "able to do it extremely well") and satisfaction (where $1=$ "not satisfied at all" and $10=$ "extremely satisfied"). We obtained the mean scores for performance and satisfaction by summing the ratings for performance and satisfaction over the prioritized problems and dividing them by the number of prioritized problems. For an evaluation over time, at a later date the client again rates the performance and satisfaction regarding the prioritized problems of the first COPM interview. Mean scores can be compared with the mean scores of the first COPM.

To assess the criterion responsiveness, we used a transition index [37-38] to measure the perceived change in the problems as prioritized by the COPM. The perceived change in problems was graded on a 7-point ordinal scale, where 1 = "totally diminished" and 7 = "much worse." The transition index was pretested in a small group ( $n=$ 10 outpatients) and did distinguish between improved and unimproved patients. Patient-reported health transition questions that describe the magnitude and direction of change in general or specific health over a given period are a valid approach to measuring change and have been widely used as external criteria in the evaluation of responsiveness [38-39].

We assessed the construct responsiveness by comparing the COPM scores with the scores for the Sickness Impact Profile (SIP68), the Disability and Impact Profile (DIP), and the Impact on Participation and Autonomy (IPA). All these instruments include scales and/or subscales on the activities and participation domain of the International Classification of Functioning, Disability and Health [40] and aim to measure the impact or importance of a condition on functioning.

The SIP68, a generic measure used for assessing the impact of illness on daily functioning and behavior [4142], consists of 68 items that are all dichotomously scored. The items are categorized into six subscales: somatic autonomy (e.g., getting dressed, transfers), mobility control (behavior related to walking and arm function), psychological autonomy and communication (e.g., concentration, alertness, talking), emotional stability (the effect of health status on emotional behavior), social behavior, and "mobility range" (instrumental daily activities). Subscale scores and an overall score can be calculated from the number of confirmed sickness impact items. The SIP68 is a reliable instrument and a valid discriminative method able to detect changes in healthrelated functional status [41].

The DIP is a self-administered questionnaire concerning activities that may be restricted because of a disabling disease [43-44]. It consists of 39 questions about symptoms ( 3 items) and the five domains: mobility (10 items), self-care (6 items), social activities (10 items), communication (5 items), and psychological status (5 items). Every question is rated on a 0 - to 10 -point scale for the current level of disability (0: maximal disability, 10: no disability) and for the importance (impact) of that particular disability (0: not important at all, 10: most important of all). The validity of the DIP is satisfactory [44-45] and its reliability is acceptable [46].

Weighted scores are calculated by determining the deficit from the normal situation by subtracting the actual disability score from 10 and multiplying this deficit by the impact score for that item. This calculation results in a combined deficit score that is divided by 100 . This value is then subtracted from 1 . The result is a weighteditem score, combining aspects of the disability and the impact of this disability $[44,47]$.

The authors of the DIP defined a weighted score of $<0.50$ as a "major disruption of quality of life" [45]. However, because the COPM is not a norm-referenced measure, taking "major disruptions" as the starting point for comparison with the COPM was not feasible. Therefore, we chose a milder cutoff score; weighted scores $\leq 0.65$ are regarded as disruptions of quality of life [16].

The IPA measures self-perceived participation [4849]. The IPA, a self-administered generic questionnaire, assesses the impact of a condition on two different aspects of participation. One aspect is the perceived participation and autonomy for 31 items reflected in 5 domain scores (autonomy indoors, family role, autonomy outdoors, social relations, and work/education). The other aspect concerns the experienced problems related to aspects of participation, reflected in eight problem-experience scores. Perceived participation is scored on a 5-point rating scale, ranging from 1 (very good) to 5 (very poor). The perceived problems are scored on a 3-point rating scale ranging from 0 (no problem) to 2 (severe problem). For each domain, an overall score for the participation items is calculated, as well as one overall score for the eight problem-related experience items. The IPA is able to detect important within-person improvement over time, 
and its reliability and validity have been found to be good [48-49].

To investigate the client's opinion about the feasibility of the COPM, we developed two questionnaires to evaluate the client's perception of the COPM assessment and reassessment. The questionnaires consisted of a 9-item version for the initial COPM assessment and a short 4-item version for the COPM reassessment. The items concerned the goal, the method used to identify the perceived problems, the amount of time involved, and the COPM scores. For example, Was the aim of the interview clear to you? Was the interview an appropriate way to identify your problems? Was there enough time to tell your story? How did you experience rating the importance of your problems (was it easy/meaningful/annoying)? In the shorter reassessment version, the items about the identification of the perceived problems and the impact of scoring the importance of these problems were not included. The COPM experience could be rated as yes, partly, no, or no opinion.

\section{Procedure}

The clients were assessed twice. The assessors were blinded for the provided occupational therapy. The client and the occupational therapist planned the reassessment together 3 months after the first session or, if the therapy ended within 3 months, before the last occupational therapy session. A period of 3 months was chosen because we expected the occupational therapy to improve occupational performance by that time. The same assessor assessed each client twice, but because of difficulties in the planning, another assessor reassessed eight clients (6\%).

At the first assessment, we collected demographic information (i.e., age, diagnosis, duration of disease, sex, living situation, and cultural background) and conducted the COPM interview. At the reassessment, we asked the client to rate his/her performance and satisfaction with the prioritized problems identified during the first COPM interview. At first, we obtained scores without showing the client or the assessor the scores for that first assessment (blind scores). Later, we showed the clients their scores for the first assessment and asked them to rate their performance and satisfaction again (reflection scores).

After the first COPM assessment and the reassessment, clients completed the SIP68, DIP, IPA, and questionnaires about their opinion of the COPM assessment (9-item version) and the COPM reassessment (4-item version). After the reassessment, clients completed the tran- sition index. The treating occupational therapist received the information obtained by the COPM assessment.

\section{Data Analysis}

We assessed the responsiveness of the COPM performance and satisfaction scores by comparing the mean performance and the mean satisfaction scores of the first assessment with the mean scores of the reassessment, respectively. The data were analyzed in SPSS version 10.0 (SPSS, Inc; Chicago, Illinois).

\section{Criterion Responsiveness}

To establish to what extent the COPM is able to detect improvement over time (criterion responsiveness), we used the transition index as an external standard to measure the perception of change [37-38]. Improvement was defined as a rating of totally diminished, diminished, or slightly diminished for at least three of the five problems on the transition index. Because the perceived occupational performance problems prioritized on the COPM are often translated into therapeutic goals for improving the client's problems, the focus of this study of the COPM's responsiveness is on identifying improvement. Clients who indicated deterioration (slightly worse, worse, or much worse) for at least three of the five problems on the transition index were excluded from the analyses. We then used receiver operating characteristic (ROC) curves [32] to assess the responsiveness of the COPM. The ROC method is considered appropriate for evaluating if a measure is as good as its "gold standard" [32]. The ROC curve plots the sensitivity (true positive rate) versus 1 minus the specificity (false negative rate) for each possible cutoff point of the COPM change scores, based on the absence of improvement as defined by the transition index.

The area under the curve (AUC) for the ROC represents the probability that a client will be correctly identified by the COPM as improved. An AUC of 0.5 indicates that the COPM is a nondiscriminating test (not accurate), whereas an AUC of 1.0 implies perfect accuracy in distinguishing improved from unimproved [50]. We also used the ROC curve to select an optimum cutoff point, which reflects the COPM change score that provides the optimal distinction between improved and unimproved clients. This cutoff score is the optimal trade-off between sensitivity and specificity and is defined as the COPM change score for the data point closest to the upper left corner of the ROC curve. 


\section{Construct Responsiveness}

To study the relationship between the change in COPM scores and the change in SIP68, DIP, and IPA scores (construct responsiveness), we computed partial correlations between the reassessment scores for these measures, controlling for the scores for the initial assessment. Correlations were considered low $(<0.20)$, moderate (between 0.20 and 0.50 ), or high ( $>0.50)$ according to the recommendations of Cohen [51]. We performed a one-tailed significance test. Because the COPM focuses on activities, we expected correlations to be found on the SIP68, DIP, and IPA scales for activities but not for impairment or behavior.

\section{Feasibility and Correlations Between Performance and Satisfaction Scores}

We computed partial correlation coefficients (twotailed significance test) to assess the correlation between the mean COPM performance reassessment scores and the mean satisfaction reassessment scores, controlling for initial assessment scores. To study the differences between the performance and the satisfaction scores, we performed paired $t$-tests between the changes (difference between the initial assessment and reassessment) in the COPM mean performance and mean satisfaction scores. We performed descriptive analyses on the results of the questionnaires, assessing the client's perception of the feasibility of the COPM.

\section{RESULTS}

\section{Study Population}

Of the 243 clients invited to participate, 61 were unwilling and 30 were excluded because they did not ful- fill the inclusion criteria $(n=17)$ or could not be contacted $(n=9)$ ), or on the advice of a physician $(n=1)$ or because of planning problems $(n=3)$. In total, 152 clients were included, all of whom gave informed consent. All clients were referred to the occupational therapy in the usual way and can therefore be considered typical for occupational therapy at the participating institutions. After referral, the clients were checked only according to the inclusion criterion. No significant differences existed in age (50 \pm 15 , range $20-84$ vs $51 \pm 13$, range $25-83$ ) or sex (62\% female in both groups) between the participating and nonparticipating clients. The time interval between the first and the second assessment was $13 \pm 4$ (mean \pm standard deviation) weeks.

Incomplete data were obtained from 14 clients (first assessment $[n=7]$ and reassessment $[n=7]$ ) because of a worsening health condition $(n=3)$, termination of the occupational therapy sessions because of other priorities in the treatment $(n=3)$, death $(n=2)$, or nonresponse $(n=6)$. Complete data were obtained from 138 clients, and their characteristics are presented in Table 1.

Several issues were addressed in the COPM. In the self-care category, these included, for example, cleaning vegetables, pulling up the duvet while in bed, driving a car, getting in and out of the bath, and dressing. In the productivity category, these included, for example, walking up or down stairs while carrying materials, typing on the personal computer, visiting other companies, storing groceries, and looking after grandchildren. In the leisure category, these included, for example, playing the cello, playing outside with children, walking the dog, and other uncategorized examples such as using the telephone while lying in bed or moving again after a period of inactivity.

Table 1.

Characteristics of study population $(n=138)$. All values expressed in years.

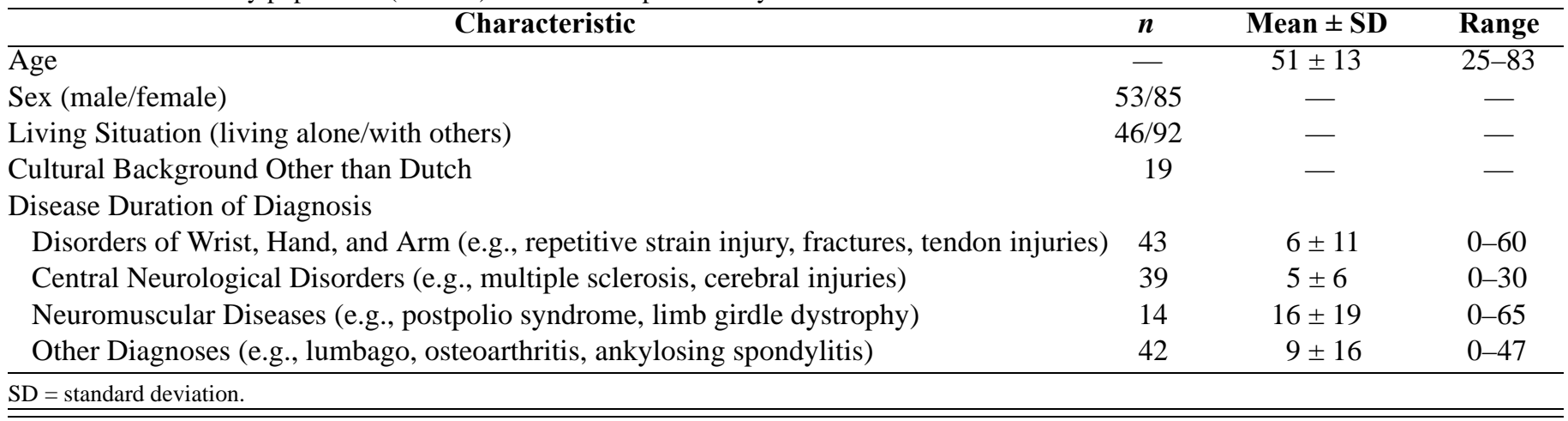




\section{Criterion Responsiveness}

We found significant differences between the mean COPM assessment and reassessment scores $(p<0.001)$. On the transition index, 78 of the 138 clients indicated an improvement (57\%), 40 clients indicated no change (29\%), and 20 clients (14\%) indicated deterioration. The clients indicating deterioration $(n=20)$ were excluded from the criterion responsiveness analyses. Table 2 shows the change scores for the mean COPM performance and satisfaction scores.

Table 2 also presents the AUCs and the cutoff values for improvement in the COPM performance and satisfaction scores. The AUCs were 0.79 (blind scores) and 0.85 (reflective scores). The optimal decision threshold (cutoff value) of the COPM for evaluating improvement perceived by the client ranged between 0.90 and 1.90 and was higher for the satisfaction scores than for the performance scores.

\section{Construct Responsiveness}

Most of the partial correlations between the COPM and the SIP68, DIP, and IPA were significant $(p<0.01)$ and positive but moderate (varying between 0.21 and 0.44 ) (Table 3). As expected, correlations between the COPM and the other measures were higher for the SIP68, DIP, and IPA subscales related to activities than for the subscales related to impairment and behavior. Low correlations were found for the SIP68 emotional stability subscale (e.g., impatience, anger) and the SIP68 psychological autonomy and communication subscale (e.g., concentration, problem-solving), the DIP communication subscale (e.g., hearing, talking, seeing), and the IPA social relations subscale (e.g., social intercourse, respect).

We found no significant correlation between the COPM and the SIP68 mobility control subscale. Fewer significant correlations existed between the COPM and the SIP68 than between the COPM and the DIP or the IPA (Table 3).

\section{Feasibility and Correlations Between Performance and Satisfaction Scores}

The partial correlation between the mean COPM performance and the satisfaction reassessment scores was $0.92(p<0.001)$. We found significant differences for the blind scores $(0.51 \pm 1.11)$, as well as for the reflection scores $(0.49 \pm 1.03)$, between the changes (reassessment minus the initial assessment) in the mean performance and the mean satisfaction scores $(p<0.001)$.

Clients' perceptions of the COPM assessment and reassessment are presented in Table 4. At the initial assessment, more than 90 percent of the clients indicated that the purpose of the COPM interview was clear and that the COPM was a good way to identify the perceived problems. At the first assessment, 22.8 percent of the clients indicated that it was easy to give scores for importance and 25.9 percent indicated that it was easy to give scores for performance and satisfaction. Approximately 80 percent indicated that it was meaningful, and 5 percent of the clients indicated that it was annoying to give scores. At the reassessment, the number of clients who indicated that it was easy to give performance and satisfaction scores increased significantly from 25.9 to 46.4 percent $(p<0.001)$.

\section{DISCUSSION}

This study focused on the responsiveness of the COPM. The criterion responsiveness of the COPM indicated good discriminatory power of the COPM to detect improvement from no improvement. The authors of the COPM manual noticed that, because the COPM is an individualized measure, the meaning of the change scores

Table 2

Change scores and responsiveness of the Canadian Occupational Performance Measure (COPM) (area under curve [AUC] and optimal cutoff value) $(n=118)$.

\begin{tabular}{|c|c|c|c|c|}
\hline \multirow{3}{*}{ Value } & \multicolumn{2}{|c|}{ COPM Performance } & \multicolumn{2}{|c|}{ COPM Satisfaction } \\
\hline & Blind & Reflection & Blind & Reflection \\
\hline & $\overline{\text { Mean } \pm \text { SD }}$ & Mean \pm SD & $\begin{array}{ll}\text { Mean } \pm \text { SD } & \text { Range }\end{array}$ & Mean \pm SD Range \\
\hline Change Score & $1.61 \pm 1.77 \quad-2.00-6.20$ & $1.61 \pm 1.70-1.80-6.20$ & $2.13 \pm 2.03-1.60-8.50$ & $2.08 \pm 2.00-1.80-8.50$ \\
\hline Optimal Cutoff Value & 1.37 & 0.90 & 1.90 & 1.45 \\
\hline
\end{tabular}


Table 3

Partial correlations between the Canadian Occupational Performance Measure (COPM) reassessment scores and reassessment scores of, respectively, categories of SIP68, DIP, and IPA questionnaires, controlling for effect of initial assessment scores (one-tailed significance test).

\begin{tabular}{|c|c|c|c|c|}
\hline \multirow{2}{*}{ Questionnaire } & \multicolumn{2}{|c|}{ COPM Performance } & \multicolumn{2}{|c|}{ COPM Satisfaction } \\
\hline & Blind & Reflection & Blind & Reflection \\
\hline \multicolumn{5}{|l|}{ SIP68 Category } \\
\hline Somatic Autonomy & $0.2090^{*}$ & $0.2292^{*}$ & $0.1677^{\dagger}$ & $0.1600^{\dagger}$ \\
\hline Mobility Control & 0.0164 & 0.0020 & 0.0322 & 0.0167 \\
\hline Social Behavior & $0.2150^{*}$ & $0.2143^{*}$ & $0.2359^{*}$ & $0.2106^{*}$ \\
\hline Emotional Stability & 0.0246 & 0.0326 & 0.0970 & 0.0880 \\
\hline Mobility Range & $0.4043^{*}$ & $0.4072^{*}$ & $0.3566^{*}$ & $0.3402^{*}$ \\
\hline Psychological Autonomy and Communication & 0.0019 & 0.0059 & 0.0155 & 0.0056 \\
\hline \multicolumn{5}{|l|}{ DIP Category } \\
\hline Symptology & 0.1412 & $0.1876^{\dagger}$ & $0.2266^{*}$ & $0.2213^{*}$ \\
\hline Mobility & $0.3983^{*}$ & $0.4200^{*}$ & $0.4240^{*}$ & $0.4362^{*}$ \\
\hline Self-Care & $0.2725^{*}$ & $0.2789^{*}$ & $0.3026^{*}$ & $0.3015^{*}$ \\
\hline Social Activities & $0.2308^{*}$ & $0.2109^{*}$ & $0.2420^{*}$ & $0.2431^{*}$ \\
\hline Communication & 0.1383 & 0.1417 & 0.1420 & $0.1473^{\dagger}$ \\
\hline Psychosocial Status & $0.2137^{*}$ & $0.2506^{*}$ & $0.2653^{*}$ & $0.3092^{*}$ \\
\hline \multicolumn{5}{|l|}{ IPA Category } \\
\hline Autonomy Indoors & $0.3463^{*}$ & $0.3221^{*}$ & $0.3853^{*}$ & $0.3671^{*}$ \\
\hline Family Role & $0.3646^{*}$ & $0.3490^{*}$ & $0.4100^{*}$ & $0.3987^{*}$ \\
\hline Autonomy Outdoors & $0.3656^{*}$ & $0.3485^{*}$ & $0.4048^{*}$ & $0.3917^{*}$ \\
\hline Social Relations & $0.1498^{\dagger}$ & 0.1290 & $0.2218^{*}$ & $0.2102^{*}$ \\
\hline Work and Education & $0.2693^{*}$ & $0.2447^{*}$ & $0.3194^{*}$ & $0.2954^{*}$ \\
\hline Total (Problem-Related Experience) & $0.3141^{*}$ & $0.3121^{*}$ & $0.3949^{*}$ & $0.3806^{*}$ \\
\hline
\end{tabular}

Table 4

Clients' perceptions of the Canadian Occupational Performance Measure (COPM) assessment and reassessment (\%) $(n=138)$.

\begin{tabular}{|c|c|c|c|c|c|c|c|c|}
\hline \multirow[b]{2}{*}{ Variable } & \multicolumn{4}{|c|}{ Assessment COPM } & \multicolumn{4}{|c|}{ Reassessment COPM } \\
\hline & Yes & Partly & No & $\begin{array}{c}\text { No } \\
\text { Opinion }\end{array}$ & Yes & Partly & No & $\begin{array}{c}\text { No } \\
\text { Opinion }\end{array}$ \\
\hline Clear Purpose & 98.6 & 1.4 & - & - & 96.4 & 2.9 & 0.7 & - \\
\hline Good Method to Identify Problems & 92.8 & 7.2 & - & - & - & - & - & - \\
\hline Sufficient Space/Time & 97.8 & 2.2 & - & - & - & - & - & - \\
\hline \multicolumn{9}{|l|}{ Giving Scores for Importance } \\
\hline Easy & 22.8 & 49.3 & 27.9 & - & - & - & - & - \\
\hline Meaningful & 80.0 & 17.0 & 1.5 & 1.5 & - & - & - & - \\
\hline Annoying & 4.5 & 13.4 & 79.9 & 2.2 & - & - & - & - \\
\hline \multicolumn{9}{|c|}{ Giving Scores for Performance and Satisfaction } \\
\hline Easy & 25.9 & 40.0 & 34.1 & - & 46.4 & 36.2 & 15.9 & 1.4 \\
\hline Meaningful & 81.6 & 14.0 & 2.2 & 2.2 & 79.7 & 14.5 & 2.2 & 3.6 \\
\hline Annoying & 5.3 & 12.0 & 81.2 & 1.5 & 2.9 & 7.2 & 87.7 & 2.2 \\
\hline
\end{tabular}


may vary for each individual, but when the COPM is used for research, setting a change level (cutoff value) a priori is best [52]. Results of the criterion responsiveness in our study showed optimum decision thresholds (cutoffs) between clients who improved and clients who did not improve. These cutoff values were lower than the 2-point difference indicated in the COPM manual as clinically important [7].

We used an external standard, a transition index, to establish the criterion responsiveness. However, the use of such indexes can be questionable because their reliability and validity are difficult to verify and because the assessment of change is psychologically difficult, as a subtraction has to be made from the present and the initial state [53]. A solution for this dilemma is to show patients their previous scores [49]. Despite some disadvantages, transition indexes are useful alternatives when a treatment of known efficacy is missing [49]. They have proven to be useful external standards against which to compare change scores on health status measures [54]. In the present study, the COPM and the transition index were both used to evaluate the client's perceived problems. The results showed that the measured changes reflected what the client considered to be a relevant change.

The construct responsiveness of the COPM was also supported in this study, because the change scores on the COPM showed significant correlations with the domains of other instruments (SIP68, DIP, and IPA) related to activities and not on the domains related to impairment and to social and emotional behavior. The absence of significant correlations can occur because, in many disorders, no clear relationship exists between impairments and either performance or problem-related experience $[7,55]$.

The significant correlations were moderate, probably because the COPM offers significant individual variance [16] because the COPM incorporates the individual client perspectives, expectations, and preferences in an outcome measure. With scoring systems that are based on individualized measures, the clients assess themselves. This method of measurement seems to show an improved sensitivity to change in health-related functional status compared with conventional methods that are less focused on the integration of individual patient perspectives [28].

The lower correlations between the COPM and the subscales of the SIP68 than between the COPM and both the DIP and the IPA can be explained because the SIP68 provides no information about the distinction between the inability to perform an activity and the perception that this is a problem.

The COPM reassessment scores can be obtained with [56] and without [7] showing clients the results of the initial assessment (reflective scoring and blind scoring). The results of our study supported the responsiveness of both types of scoring. However, the results also showed that the discriminatory power of the COPM to detect improvement was lower for the blind scores than for the reflection scores. The cutoff values for the reflection scores were also lower than for the blind scores. These results demonstrate that when the COPM is used for evaluation over time, results will be interpreted differently if the initial scores are shown prior to the reassessment. If one's primary interest is to detect changes over time, showing clients the scores of their initial assessment during the reassessment appears to help avoid problems in remembering the value of the activity as scored at the initial assessment. If one's primary interest is to detect the current perception, then showing clients their previous scores does not appear advisable [52].

The performance and satisfaction scores of the COPM in the present study were highly correlated. Significant correlations have also been found in other studies for the changes in scores $[17,22,56]$ and for the scores at the initial assessment and at the reassessment $[23,26]$. A possible reason for the significant correlations is that clients have difficulty interpreting the difference between the concepts of performance and satisfaction. If these two concepts are measuring the same feature, the necessity of using scores for both performance and satisfaction is questionable.

The results of our study also demonstrated that the change scores for satisfaction were 0.5 higher than the change scores for performance. These results are supported by Persson et al., who found in a study focusing on a pain management program that the improvement in satisfaction seemed to be greater than the actual change in occupational performance [23]. Most likely, a reevaluation of occupational performance took place [23]. An increase in satisfaction might reflect the process of adopting new skills and coping strategies and more adequate acceptance of an altered life situation [23]. By talking to the client about the differences between the performance and satisfaction scores, one can obtain important information about this process of reevaluation. Further research is needed to determine the necessity of using both scores, i.e., the performance score and the satisfaction score. 
Finally, we asked the clients about their experiences with the COPM. Several studies indicated that the use of scales for scoring may be abstract and difficult for some clients $[13,21]$. Although we also found that scoring was difficult for many clients during the first COPM assessment, clients also said they thought that the COPM was a good way to identify their problems. Also, during the reassessment, the number of clients who found the scoring easy increased significantly. Possible reasons are that clients find it easier to rate their problems with performance and their satisfaction when they have used the rating scales before or when more attention is paid to their problems during the intervention.

\section{LIMITATIONS}

In the present study, we chose to use a generic population and generic interventions to establish the responsiveness of the COPM. However, looking for differences in cutoff points for specific diagnostic groups, specific interventions, and different disease stadia or disease duration would also be interesting.

Also, in this study we focused on the capability of the COPM to detect change in time but we do not know whether the therapeutic goals were directed toward the issues reported on the COPM. The results of the COPM assessment were given to the occupational therapists to use these for therapeutic purposes, but the occupational therapists were free in their choice to use this information.

In our analysis, we also focused on improvement in time because we assumed that mostly the prioritized problems on the COPM are translated into therapeutic goals. Because we have not checked this assumption, one can question whether excluding the deteriorated patients was a good decision. Also interesting to know would be whether clients are deteriorated in time, e.g., because no therapy was provided or because the clients suffer from a progressive disease.

\section{CONCLUSIONS}

Despite these limitations, our study has demonstrated that the COPM is an individualized, client-centered outcome measure that is sensitive to changes in the occupational performance and satisfaction of the client's most important problems in daily functioning. These changes over time were in accordance with the changes detected by other measurement instruments. Since both the construct and the criterion responsiveness of the COPM are supported by the results of this study, we conclude that the changes in the COPM scores appeared to validly represent the occupational performance of the client over time.

\section{ACKNOWLEDGMENTS}

\section{Author Contributions:}

Study concept and design: I. C. J. M. Eyssen, M. P. M. Steultjens, J. Dekker.

Acquisition of data: I. C. J. M. Eyssen, T. A. M. Oud, E. M. Bolt, A. Maasdam.

Analysis and interpretation of data: I. C. J. M. Eyssen, M. P. M. Steultjens, T. A. M. Oud, J. Dekker.

Drafting of manuscript: I. C. J. M. Eyssen, T. A. M. Oud. Critical revision of manuscript for important intellectual content:

I. C. J. M. Eyssen, T. A. M. Oud, E. M. Bolt, A. Maasdam, J. Dekker, M. P. M. Steultjens.

Statistical analysis: I. C. J. M. Eyssen, M. P. M. Steultjens.

Study supervision: J. Dekker.

Financial Disclosures: The authors have declared that no competing interests exist.

Funding/Support: This material was based on work supported by ZonMw, The Netherlands Organisation for Health Research and Development, grant 1310.0005 .

Institutional Review: The local ethics committees of the VU University Medical Centre and the Academic Medical Centre in Amsterdam, the Netherlands, approved this study, and the authors obtained informed consent from all participating patients.

Participant Follow-Up: The authors have sent an information sheet to all participants with general information about the research and with the invitation to contact them for publications about the results of this study.

\section{REFERENCES}

1. Health topics: Rehabilitation [Internet]. Geneva (Switzerland): World Health Organization; 2010. Available from: http://www.who.int/topics/rehabilitation/en/.

2. Carpenter L, Baker GA, Tyldesley B. The use of the Canadian occupational performance measure as an outcome of a pain management program. Can J Occup Ther. 2001;68(1): 16-22. [PMID: 11233684]

3. Wressle E, Samuelsson K, Henriksson C. Responsiveness of the Swedish version of the Canadian Occupational Performance Measure. Scand J Occup Ther. 1999;6(2):84-89. DOI:10.1080/110381299443771

4. Townsend E, Sue Stanton; Canadian Association of Occupational Therapists. Enabling occupation: An occupational therapy perspective. Ottawa (Canada): Canadian Association of Occupational Therapists; 2002. 
5. Carson R. Are you listening? Client-centred practice in an American acute care rehabilitation hospital: a case study. Occup Ther Now. 1999;1(3):5-7 [cited 2011 Mar 22]. Available from: http://www.caot.ca/otnow/may99-eng/ may99-client.cfm/

6. Riemsma RP, Forbes CA, Glanville JM, Eastwood AJ, Kleijnen J. General health status measures for people with cognitive impairment: Learning disability and acquired brain injury. Health Technol Assess. 2001;5(6):1-100. [PMID: 11319989]

7. Law M, Baptiste S, Carswell A, McColl MA, Polatajko H, Pollock N. Canadian Occupational Performance Measure. 4th ed. Toronto (Canada): Canadian Association of Occupational Therapists; 2005.

8. Townsend EA, Polatjako HJ. Enabling occupation II: Advancing an occupational therapy vision for health, wellbeing \& justice through occupation. Ottawa (Canada): Canadian Association of Occupational Therapists; 2007.

9. Cup EH, Scholte op Reimer WJ, Thijssen MC, Kuyk-Minis MA. Reliability and validity of the Canadian Occupational Performance Measure in stroke patients. Clin Rehabil. 2003;17(4):402-9. [PMID: 12785249$]$

DOI:10.1191/0269215503cr635oa

10. Eyssen IC, Beelen A, Dedding C, Cardol M, Dekker J. The reproducibility of the Canadian Occupational Performance Measure. Clin Rehabil. 2005;19(8):888-94.

[PMID: 16323388] DOI:10.1191/0269215505cr883oa

11. Pan AW, Chung L, Hsin-Hwei G. Reliability and validity of the Canadian Occupational Performance Measure for clients with psychiatric disorders in Taiwan. Occup Ther Int. 2003;10(4):269-77. [PMID: 14647540] DOI:10.1002/oti.190

12. Sewell L, Singh SJ. The Canadian Occupational Performance Measure: Is it a reliable measure in clients with chronic obstructive pulmonary disease? $\mathrm{Br} \mathrm{J}$ Occup Ther. 2001; 64(6):305-10.

13. Carswell A, McColl MA, Baptiste S, Law M, Polatajko H, Pollock N. The Canadian Occupational Performance Measure: A research and clinical literature review. Can J Occup Ther. 2004;71(4):210-22. [PMID: 15586853]

14. Bodiam C. The use of the Canadian Occupational Performance Measure for the assessment of outcome on a neurorehabilitation unit. Br J Occup Ther. 1999;62(3):123-26.

15. Chan CC, Lee TM. Validity of the Canadian Occupational Performance Measure. Occup Ther Int. 1997;4(3):229-47. DOI:10.1002/oti.58

16. Dedding C, Cardol M, Eyssen IC, Dekker J, Beelen A. Validity of the Canadian Occupational Performance Measure: A client-centred outcome measurement. Clin Rehabil. 2004;18(6):660-67. [PMID: 15473118]

DOI:10.1191/0269215504cr746oa
17. McColl MA, Paterson M, Davies D, Doubt L, Law M. Validity and community utility of the Canadian Occupational Performance Measure. Can J Occup Ther. 2000; 67(1):22-30. [PMID: 10695166]

18. Verkerk GJ, Wolf MJ, Louwers AM, Meester-Delver A, Nollet F. The reproducibility and validity of the Canadian Occupational Performance Measure in parents of children with disabilities. Clin Rehabil. 2006;20(11):980-88.

[PMID: 17065541]

DOI:10.1177/0269215506070703

19. Chenq YH, Rodger S, Polatjko H. Experiences with the COPM and client-centred practice in adult neurorehabilitation in Taiwan. Occup Ther Int. 2002;9(3):167-84.

[PMID: 12921096]

DOI:10.1002/oti.163

20. Donnelly C, Eng JJ, Hall J, Alford L, Giachino R, Norton $\mathrm{K}$, Kerr DS. Client-centred assessment and the identification of meaningful treatment goals for individuals with a spinal cord injury. Spinal Cord. 2004;42(5):302-7.

[PMID: 14993893]

DOI:10.1038/sj.sc.3101589

21. Donnelly C, Carswell A. Individualized outcome measures: A review of the literature. Can J Occup Ther. 2002; 69(2):84-94. [PMID: 11977872]

22. Law M, Polatjko H, Pollock N, McColl MA, Carswell A, Baptiste S. Pilot testing of the Canadian Occupational Performance Measure: Clinical and measurement issues. Can J Occup Ther. 1994;61(4):191-97. [PMID: 10137673]

23. Persson E, Rivano-Fischer M, Eklund M. Evaluation of changes in occupational performance among patients in a pain management program. J Rehabil Med. 2004;36(2):85-91. [PMID: 15180223] DOI:10.1080/16501970310019142

24. Samuelsson KA, Tropp H, Gerdle B. Shoulder pain and its consequences in paraplegic spinal cord-injured, wheelchair users. Spinal Cord. 2004;42(1):41-46. [PMID: 14713943] DOI:10.1038/sj.sc.3101490

25. Wressle E, Marcusson J, Henriksson C. Clinical utility of the Canadian Occupational Performance Measure-Swedish version. Can J Occup Ther. 2002;69(1):40-48. [PMID: 11852689]

26. Wressle E, Lindstrand J, Neher M, Marcusson J, Henriksson C. The Canadian Occupational Performance Measure as an outcome measure and team tool in a day treatment programme. Disabil Rehabil. 2003;25(10):497-506. [PMID: 12745961] DOI:10.1080/0963828031000090560

27. Guyatt GH, Kirshner B, Jaeschke R. Measuring health status: What are the necessary measurement properties? J Clin Epidemiol. 1992;45(12):1341-45. [PMID: 1460470] DOI:10.1016/0895-4356(92)90194-R 
28. Middel B, Van Sonderen E. Statistical significant change versus relevant or important change in (quasi) experimental design: Some conceptual and methodological problems in estimating magnitude of intervention-related change in health services research. Int J Integr Care. 2002;2:e15. [PMID: 16896390]

29. Mokkink LB, Terwee CB, Patrick DL, Alonso J, Stratford PW, Knol DL, Bouter LM, De Vet HC. The COSMIN study reached international consensus on taxonomy, terminology, and definitions of measurement properties for healthrelated patient-reported outcomes. J Clin Epidemiol. 2010; 63(7):737-45. [PMID: 20494804]

DOI:10.1016/j.jclinepi.2010.02.006

30. Bot SD, Terwee CB, Van der Windt DA, Bouter LM, Dekker J, De Vet HC. Clinimetric evaluation of shoulder disability questionnaires: A systematic review of the literature. Ann Rheum Dis. 2004;63(4):335-41. [PMID: 15020324] DOI:10.1136/ard.2003.007724

31. Terwee CB, Dekker FW, Wiersinga WM, Prummel MF, Bossuyt PM. On assessing responsiveness of health-related quality of life instruments: Guidelines for instrument evaluation. Qual Life Res. 2003;12(4):349-62. [PMID: 12797708$]$ DOI:10.1023/A:1023499322593

32. Mokkink LB, Terwee CB, Patrick DL, Alonso J, Stratford PW, Knol DL, Bouter LM, De Vet HC. The COSMIN checklist for assessing the methodological quality of studies on measurement properties of health status measurement instruments: An international Delphi study. Qual Life Res. 2010;19(4):539-49. [PMID: 20169472]

DOI:10.1007/s11136-010-9606-8

33. Mokkink LB, Terwee CB, Knol DL, Stratford PW, Alonso J, Patrick DL, Bouter LM, De Vet HC. The COSMIN checklist for evaluating the methodological quality of studies on measurement properties: A clarification of its content. BMC Med Res Methodol. 2010;10:22.

[PMID: 20298572]

DOI:10.1186/1471-2288-10-22

34. Effing E, Dirx E, Sleegers EJ, Van Meeteren N. De responsiviteit van de COPM, ARA en SODA voor veranderingen in handvaardigheid bij plastisch-chirurgische handpatienten [The responsiveness of the COPM, ARA, and SODA to detect changes in hand skills of patients after plastic surgery.] Nederlands Tijdschrift voor Ergotherapie. 1999;27(3):109-16 [cited 2011 Mar 22]. Available from: http://www.boomlemma.nl/

35. Case-Smith J. Outcomes in hand rehabilitation using occupational therapy services. Am J Occup Ther. 2003;57(5): 499-506. [PMID: 14527111]

DOI:10.5014/ajot.57.5.499

36. Van Duijn HM, Niezen AA, Cardol M, Corder-Bartels IE, Verkerk GJQ. Canadees meetinstrument voor handelingen en vaardigheden [Canadian Occupational Performance
Measure (COPM)—Dutch version]. Amsterdam (the Netherlands): AMC/VU University Medical Centre; 1999.

37. Husted JA, Cook RJ, Farewell VT, Gladman DD. Methods for assessing responsiveness: A critical review and recommendations. J Clin Epidemiol. 2000;53(5):459-68.

[PMID: 10812317]

DOI:10.1016/S0895-4356(99)00206-1

38. Fitzpatrick R, Ziebland S, Jenkinson C, Mowat A, Mowat A. Transition questions to assess outcomes in rheumatoid arthritis. Br J Rheumatol. 1993;32(9):807-11. [PMID: 8369891] DOI:10.1093/rheumatology/32.9.807

39. Haywood KL, Garratt AM, Jordan K, Dziedzic K, Dawes PT. Disease-specific, patient-assessed measures of health outcome in ankylosing spondylitis: Reliability, validity and responsiveness. Rheumatology (Oxford). 2002;41(11):1295-302.

[PMID: 12422003]

DOI:10.1093/rheumatology/41.11.1295

40. World Health Organization. International classification of functioning, disability and health: ICF. Geneva (Switzerland): World Health Organization; 2001.

41. De Bruin AF, Diederiks JP, De Witte LP, Stevens FC, Philipsen $\mathrm{H}$. Assessing the responsiveness of a functional status measure: The Sickness Impact Profile versus the SIP68. J Clin Epidemiol. 1997;50(5):529-40. [PMID: 9180645] DOI:10.1016/S0895-4356(97)00047-4

42. Nanda U, McLendon PM, Andresen EM, Armbrecht E. The SIP68: An abbreviated sickness impact profile for disability outcomes research. Qual Life Res. 2003;12(5):583-95.

[PMID: 13677503]

DOI:10.1023/A:1025036325886

43. Cohen L, Pouwer F, Pfennings LE, Lankhorst GJ, Van der Ploeg HM, Polman CH, Adèr HJ, Jønnson A, Vleugels L. Factor structure of the Disability and Impact Profile in patients with multiple sclerosis. Qual Life Res. 1999;8(1-2):141-50. [PMID: 10457747] DOI:10.1023/A:1026481029191

44. Lankhorst GJ, Jelles F, Smits RC, Polman CH, Kuik DJ, Pfennings LE, Cohen L, Van der Ploeg HM, Ketelaer P, Vleugels L. Quality of life in multiple sclerosis: The disability and impact profile (DIP). J Neurol. 1996;243(6): 469-74. [PMID: 8803821] DOI:10.1007/BF00900502

45. Pfennings LE, Van der Ploeg HM, Cohen L, Bramsen I, Polman CH, Lankhorst GJ, Vleugels L. A health-related quality of life questionnaire for multiple sclerosis patients. Acta Neurol Scand. 1999;100(3):148-55. [PMID: 10478577] DOI:10.1111/j.1600-0404.1999.tb00730.x

46. Pfennings L, Cohen L, Van der Ploeg H, Polman C, Lankhorst G. Reliability of two measures of health-related quality of life in patients with multiple sclerosis. Percept Mot Skills. 1998;87(1):111-14. [PMID: 9760635] 
47. Laman H, Lankhorst GJ. Subjective weighting of disability: An approach to quality of life assessment in rehabilitation. Disabil Rehabil. 1994;16(4):198-204.

[PMID: 7812020]

DOI:10.3109/09638289409166613

48. Cardol M, De Haan RJ, De Jong BA, Van den Bos GA, De Groot IJ. Psychometric properties of the Impact on Participation and Autonomy Questionnaire. Arch Phys Med Rehabil. 2001;82(2):210-16. [PMID: 11239312] DOI:10.1053/apmr.2001.18218

49. Cardol M, Beelen A, Van den Bos GA, De Jong BA, De Groot IJ, De Haan RJ. Responsiveness of the Impact on Participation and Autonomy questionnaire. Arch Phys Med Rehabil. 2002;83(11):1524-29. [PMID: 12422319] DOI:10.1053/apmr.2002.35099

50. Streiner DL, Norman GR. Health measurement scales: A practical guide to their development and use. 2nd ed. Oxford (UK): Oxford University Press; 1995.

51. Cohen J. Statistical power analysis for the behavioral sciences. New York (NY): Academic; 1969.

52. Law M, Baptiste S, Carswell A, McColl M, Polatajko H, Pollock N. COPM: Questions and answers [Internet]. Updated 2004 Mar 27. Available from: www.caot.ca/copm/ questions.html.

53. Norman GR, Stratford P, Regehr G. Methodological problems in the retrospective computation of responsiveness to change: The lesson of Cronbach. J Clin Epidemiol. 1997; 50(8):869-79. [PMID: 9291871] DOI:10.1016/S0895-4356(97)00097-8
54. Deyo RA, Inui TS. Toward clinical applications of health status measures: Sensitivity of scales to clinically important changes. Health Serv Res. 1984;19(3):275-89. [PMID: 6746293]

55. Badley EM. An introduction to the concepts and classifications of the International Classification of Impairments, Disabilities, and Handicaps. Disabil Rehabil. 1993;15(4): 161-78. [PMID: 8219245] DOI:10.3109/09638289309166008

56. Walsh DA, Kelly SJ, Johnson PS, Rajkumar S, Bennetts K. Performance problems of patients with chronic low-back pain and the measurement of patient-centered outcome. Spine. 2004;29(1):87-93. [PMID: 14699282] DOI:10.1097/01.BRS.0000105533.09601.4F

Submitted for publication June 3, 2010. Accepted in revised form November 22, 2010.

This article and any supplementary material should be cited as follows:

Eyssen ICJM, Steultjens MPM, Oud TAM, Bolt EM, Maasdam A, Dekker J. Responsiveness of the Canadian Occupational Performance Measure. J Rehabil Res Dev. 2011;48(5):517-28.

DOI:10.1682/JRRD.2010.06.0110

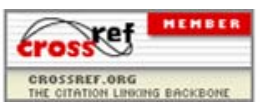

